\title{
Comparison of visceral adipose tissue DNA methylation and gene expression profiles in female adolescents with obesity
}

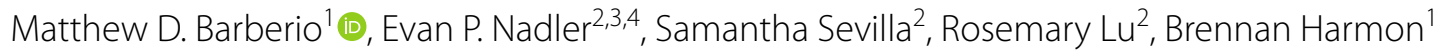
and Monica J. Hubal ${ }^{1,5^{*}}$

\begin{abstract}
Background: Epigenetic changes in visceral adipose tissue (VAT) with obesity and their effects on gene expression are poorly understood, especially during emergent obesity in youth. The current study tested the hypothesis that methylation and gene expression profiles of key growth factor and inflammatory pathways are altered in VAT from obese compared to non-obese youth.

Methods: VAT samples from adolescent females grouped as Lean $(L ; n=15 ;$ age $=15 \pm 3$ years, $B M I=21.9 \pm 3.0 \mathrm{~kg} /$ $\left.\mathrm{m}^{2}\right)$ or Obese $\left(\mathrm{Ob} ; \mathrm{n}=15\right.$, age $=16 \pm 2$ years, $\left.\mathrm{BMI}=45.8 \pm 9.8 \mathrm{~kg} / \mathrm{m}^{2}\right)$ were collected. Global methylation $(\mathrm{n}=20)$ and gene expression $(N=30)$ patterns were profiled via microarray and interrogated for differences between groups by ANCOVA $(p<0.05)$, followed by biological pathway analyses.

Results: Overlapping differences in methylation and gene expression in 317 genes were found in VAT from obese compared to lean groups. PI3K/AKT Signaling ( $p=1.83 \times 10^{-6} ; 11 / 121$ molecules in dataset/pathway) was significantly overrepresented in Ob VAT according to pathway analysis. Upregulations in the PI3K/AKT signaling pathway mRNAs TFAM $(p=0.03$; fold change $=1.8)$ and PPP2R5C $(p=0.03, F C=2.6)$ were confirmed via qRT-PCR.

Conclusion: Our analyses show obesity-related differences in DNA methylation and gene expression in visceral adipose tissue of adolescent females. Specifically, we identified methylation site/gene expression pairs differentially regulated and mapped these differences to pathways including PI3K/AKT signaling, suggesting that PI3K/AKT signaling pathway dysfunction in obesity may be driven in part by changes in DNA methylation.
\end{abstract}

Keywords: Obesity, Adipose tissue, Epigenetics, Gene expression

\section{Background}

Obesity is a chronic condition characterized by the accumulation of adipose tissue, which plays a critical role in metabolic dysfunction [1]. Regionalized accumulation of visceral adipose tissue (VAT) has been strongly linked to the incident development of cardiovascular disease and cardiometabolic diseases such as Type 2 diabetes mellitus (T2DM) and stroke $[1,2]$. While adipose tissue is recognized as an important endocrine organ responsible

\footnotetext{
*Correspondence: mhubal@iupui.edu

${ }^{1}$ Center for Genetic Medicine Research, Children's Research Institute,

Children's National Medical Center, Washington, DC, USA

Full list of author information is available at the end of the article
}

for the secretion of multiple pro-inflammatory cytokines and adipokines, the molecular adaptations of adipose tissue to obesity are less clearly understood $[3,4]$, as are the specific molecular mechanisms driving obesity co-morbidities like insulin resistance.

Heritable and lifestyle (e.g. diet and physical activity) factors play crucial roles in the development of obesity, resulting in a complex pathogenesis of obesity and its co-morbidities [5]. Epigenetic regulation represents the intersection between genetics and the obesogenic environment and an increased interest in the role of epigenetics in the development of obesity has developed over the past decade [6]. DNA methylation is a key type of epigenetic modification that has received attention because of 
its tissue-specificity and responsiveness to environmental changes [7]. Methylation mainly occurs at the $5^{\prime}$ position of cytosine residues occurring in CG dinucleotide (CpG sites), which are unevenly distributed in the genome. The interest of CpG methylation in complex disease stems from its typical role as a suppressor of gene expression through the methylation of gene promoters [7].

Current evidence suggests DNA methylation is modified across multiple tissues in patients with obesity and obesity co-morbidities $[8,9]$. Barres et al. [10] demonstrated in skeletal muscle that obesity resulted in genomewide hyper-methylation of promoter regions that was reversed by weight loss following bariatric surgery. Studies analyzing subcutaneous adipose tissue (SAT) have demonstrated a dynamic methylome in response to acute and chronic bouts of exercise [11], and have linked methylation levels to clinical measures such as blood glucose homeostasis [12]. In VAT, over $8000 \mathrm{CpG}$ sites were found to be differentially-methylated in individuals with obesity and metabolic syndrome, as compared to individuals with obesity but without metabolic syndrome [13]. While these, and other, investigations provide insight into epigenetic changes with obesity, these data do not give us a comprehensive pattern of differential methylation with obesity. Data are particularly lacking that couple methylation data with gene expression data in the same samples, which would provide powerful insight into the functional consequences of changes in DNA methylation $[14,15]$.

Studies addressing adipose tissue global gene expression profiles and global DNA methylation in obesity have been limited to mainly adult cohorts [11-13, 16, 17], while available studies in adolescent cohorts have used non tissue specific whole blood genomic DNA [18, 19]. In this investigation, we utilize adolescent cohorts with vastly different amounts of VAT, allowing us to identify genomic and epigenetic modifications driven by obesity during this period of dynamic growth and maturation. Understanding how the obesogenic environment affects both DNA methylation and gene expression in VAT tissue with a global unbiased approach can help identify new pathways and molecular targets that can be further tested for their role in tissue dysfunction, as well as their potential targets for therapeutics and diagnostics. We tested the hypothesis that key growth and inflammatory pathways would be epigenetically-and transcriptionallyaltered with obesity in adolescent females, as compared to lean age-matched controls.

\section{Methods}

\section{Subjects}

Adolescent (age 12-19) females grouped as either Lean (L; body mass index $(\mathrm{BMI})<25 ; \mathrm{n}=15)$ or Obese $(\mathrm{Ob}$, $\mathrm{BMI}>35 ; \mathrm{n}=15)$ were recruited to participate in this study. Three races (African-American, Caucasian and Hispanic) were represented in equal numbers (5 L; $5 \mathrm{Ob}$ each). Subcohort sample size of $n=5$ was supported by pilot data from adults with a similar design, in which 4811 mRNAs were differentially expressed in $\mathrm{Ob}(\mathrm{n}=5)$ versus $\mathrm{L}(\mathrm{n}=4)$ adults (unpublished data). Lean patients were recruited from non-bariatric abdominal surgeries (appendectomies and cholecystectomies), while subjects with obesity were recruited prior to bariatric surgery at Children's National Medical Center. Known clinical diagnoses and medications at the time of surgery are listed below per group $-\mathrm{N}=1$ per diagnosis/medication unless otherwise noted. Lean cohort: sickle cell anemia, localized peritonitis, ulcerative colitis, Crohn's disease, acid reflux, Remicade $(\mathrm{n}=2)$, Albuterol, and prednisone. Obese cohort: asthma $(n=4)$, sleep apnea $(n=3)$, insulin resistance, hypertension, polycystic ovary syndrome, appendicitis, cholecystitis, sickle cell trait, pseudotumor cerebri, hypothyroidism, albuterol, prednisone, lisinopril, levothyroxine, and diamox. Inclusion criteria for the study included qualification for surgery (bariatric and abdominal) as well as a willingness to comply with the study parameters. Bariatric surgery patients had completed a protein-sparing modified fast $(\sim 1000 \mathrm{kcal} /$ day; 50-60 g protein) for 2 weeks prior to their date of surgery. All operations took place after a minimum 12 -h overnight fasting per standard surgical practices. Patients provided assent and legal guardians signed written informed consents as approved by the Children's National Medical Center Institutional Review Board. Subject characteristics are listed in Table 1.

\section{Sample collection}

Visceral adipose (VAT) was collected from the omentum during surgery, immediately frozen in liquid nitrogen and stored at $-80^{\circ} \mathrm{C}$ until further processing.

\section{DNA isolation and VAT global DNA methylation analysis}

A representative sub-cohort of $(n=20 ; 10 \mathrm{~L} ; 10 \mathrm{Ob})$ of subjects from the entire study cohort $(\mathrm{N}=30)$ was chosen for global DNA methylation analysis based on tissue availability and DNA quality. DNA was isolated from $\sim 50 \mathrm{mg}$ of tissue using the QIAamp DNeasy Tissue Kit (Qiagen Inc.; Germantown, MD). DNA quality and quantity were analyzed using the NanoDrop 8000 UVVis spectrophotometer (Thermo Scientific; Waltham, MA). Samples all had 260:280 $\mathrm{nm}$ ratios $>1.8$. DNA was diluted to $25 \mathrm{ng} / \mu \mathrm{l}$ and a total of $500 \mathrm{ng}$ was bisulfate converted with the EZ DNA Methylation Kit (Zymo Research, Orange, CA), using the alternative incubation methods recommended for the Illumina Infinium Methylation Assay (Illumina, Inc., San Diego, CA; Accession: GSE88940). Bisulfite converted DNA (4 ul) was analyzed 
Table 1 Participant characteristics

\begin{tabular}{|c|c|c|c|c|c|}
\hline Subjects & $\mathbf{N}$ & Age (year) & Height $(\mathrm{cm})$ & Weight $(\mathbf{k g})^{a}$ & $\mathrm{BMI}^{\mathrm{a}}$ \\
\hline \multicolumn{6}{|l|}{ Gene expression cohort } \\
\hline Lean & 15 & $15 \pm 2$ & $161 \pm 6$ & $56.3 \pm 11.1$ & $21.6 \pm 2.7$ \\
\hline African American & 5 & $16 \pm 3$ & $162 \pm 8$ & $60.3 \pm 14.2$ & $22.4 \pm 3.7$ \\
\hline Caucasian & 5 & $16 \pm 1$ & $162 \pm 7$ & $55.6 \pm 9.3$ & $21.2 \pm 2.0$ \\
\hline Hispanic & 5 & $13 \pm 2$ & $158 \pm 5$ & $53.3 \pm 9.3$ & $21.1 \pm 2.0$ \\
\hline Obese & 15 & $17 \pm 2$ & $162 \pm 8$ & $124.4 \pm 29$ & $47.0 \pm 9.7$ \\
\hline African American & 5 & $16 \pm 2$ & $165 \pm 7$ & $140.2 \pm 20.6$ & $51.7 \pm 9.8$ \\
\hline Caucasian & 5 & $16 \pm 2$ & $163 \pm 10$ & $111.5 \pm 37.7$ & $41.5 \pm 9.2$ \\
\hline Hispanic & 5 & $13 \pm 2$ & $158 \pm 8$ & $121.3 \pm 23,6$ & $47.8 \pm 9.0$ \\
\hline \multicolumn{6}{|c|}{ DNA methylation cohort } \\
\hline Lean & 10 & $15 \pm 3$ & $162 \pm 7$ & $57.5 \pm 2.9$ & $21.9 \pm 3.0$ \\
\hline African American & 4 & $16 \pm 3$ & $160 \pm 7$ & $57.2 \pm 14.7$ & $21.8 \pm 4.0$ \\
\hline Caucasian & 2 & $16 \pm 1$ & $166 \pm 9$ & $64.5 \pm 12.2$ & $22.9 \pm 1.6$ \\
\hline Hispanic & 4 & $13 \pm 1$ & $159 \pm 5$ & $54.8 \pm 10.1$ & $21.4 \pm 2.6$ \\
\hline Obese & 10 & $15 \pm 2$ & $159 \pm 7$ & $114.2 \pm 28.5$ & $44.8 \pm 9.8$ \\
\hline African American & 4 & $17 \pm 3$ & $164 \pm 7$ & $148.8 \pm 8.7$ & $55.6 \pm 5.3$ \\
\hline Caucasian & 4 & $16 \pm 2$ & $159 \pm 5$ & $95.4 \pm 12.6$ & $37.9 \pm 5.0$ \\
\hline Hispanic & 2 & $16 \pm 1$ & $153 \pm 9$ & $98.2 \pm 3.0$ & $42.1 \pm 6.1$ \\
\hline
\end{tabular}

Data are mean $\pm S D$

Methylation cohort represents a subcohort of the gene expression cohort; no statistical significance for phenotype data between the gene expression and methylation cohorts was found

$B M I$ body mass index $=$ weight $(\mathrm{kg}) /$ height $(\mathrm{m})^{2}$

a Significant difference $(\mathrm{p}<0.05)$ between lean and obese groups

in a balanced design using Infinium Human Methylation 450 BeadChip Arrays (Illumina, Inc.) per manufacturer's protocol. BeadChips were scanned on an Illumina iScan System and data were analyzed with Genome Studio software (Illumina, Inc.).

\section{RNA isolation and VAT global gene expression analysis}

RNA was isolated from $200 \mathrm{mg}$ of VAT $(\mathrm{N}=30)$ using the RNeasy Lipid Tissue Mini Kit (Qiagen). RNA quality and quantity were analyzed using a NanoDrop spectrophotometer as described above, with all samples having 260:280 ratios $>1.8$. Global VAT gene expression was analyzed using Affymetrix Hu133 Plus 2.0 microarrays (Affymetrix, Santa Clara, CA; Accession: GSE88837). Briefly, extracted RNA was twice amplified using Affymetrix GeneChip 3' IVT Express per manufacturer protocol. Biotinylated cRNA $(30 \mu \mathrm{g})$ was hybridized to the microarrays. For resultant data, CEL files were imported into Affymetrix Expression Console and CHP files were generated using the PLIER (Probe Logarithmic Intensity Error) algorithm (Affymetrix). Standard quality control measures for adequate amplifications, thresholds for appropriate scaling factors, and RNA integrity (GAPDH $3^{\prime} / 5^{\prime}$ and HSAC07 $3^{\prime} / 5^{\prime}$ ) were used [20]. Samples not meeting quality control standards at any point in the above-described process were reprocessed from original total RNA.

\section{Microarray data analyses}

VAT DNA methylation arrays were analyzed in Illumina's Genome Studio software. Raw $\beta$-methylation scores ( $\beta=$ intensity of the methylated allele $(\mathrm{M}) /$ (intensity of the unmethylated allele $(U)+M)+100$ ) were generated and checked for quality based on manufacturer suggestions. $\beta$-values were converted to $M$-values $\left(M=\log ^{2}(\beta /\right.$ $(1-\beta))$ ), which represent a statistically valid method for analysis of differential methylation [21], using the $\mathrm{R}$ statistical environment [22]. Differential methylation between $\mathrm{Ob}$ and $\mathrm{L}$ was assessed using $\mathrm{M}$-values. For ease of biological interpretation, $M$-values have been converted back to $\beta$-values; mean $\beta$-values were calculated as the average of all $\beta$-values for each group and are presented as $\%$ methylation (\% methylation $=\beta$-values * 100). The Illumina Infinium Methylation Assay contains two separate assays (Infinium I and Infinium II), which perform differently [23]. Thus, average DNA methylation for Infinium I and Infinium II probes were calculated and are presented independently. For DNA methylation analysis, probes containing SNPs were removed for further analysis due to cross-reactivity [24]. Methylation 
microarray data have been archived to the Gene Expression Omnibus (GSE88940).

For gene expression analyses, PLIER data were imported into Partek Genomics Suite (Partek, Inc.; St. Louis, MO) and $\log _{2}$ transformed for further analyses. Differential global DNA methylation and gene expression between $\mathrm{Ob}$ and $\mathrm{L}$ groups were analyzed in Partek via 1-way ANCOVA with age, ethnicity, and body mass index (BMI) covariates. Given the range of BMIs present in our study (particularly within the Ob group), we accounted for BMI as a covariate in all analyses. Probes with a $p<0.05$ were considered significant in both analyses and used for further analyses. Gene lists from global DNA methylation and gene expression analyses were then explored for overlapping genes in the Genome Reference Consortium GRCh38 build. Genes found to be significantly different between groups for both global DNA methylation and gene expression were used for biological interpretation via pathway analysis (Fig. 1). It is important to note that we chose a more lenient significance $(\mathrm{p}<0.05)$ cutoff at the individual gene/methylation site stage because the likelihood of false positive findings is exponentially lowered both by cross-mapping gene expression to methylation results and the use of downstream pathway analyses (which would weed out any random errors due to its reliance on relatedness of results).
Gene expression microarray data have been archived to the Gene Expression Omnibus (GSE88837).

\section{Real-time PCR validation of target genes}

Selected microarray results were confirmed via real-time polymerase chain reaction (qPCR) in a larger cohort of 34 $(\mathrm{Ob}=19, \mathrm{~L}=15$; Additional file 1: Table S1) subjects with available RNA. No statistical differences in demographics were found between this larger cohort and either microarray cohort. RNA $(2 \mu \mathrm{g})$ was reversed-transcribed into cDNA using the SuperScript III Reverse Transcription kit (Invitrogen Corp.; Carlsbad, CA). PCR was performed in triplicate on an Applied Biosystems 7900HT Fast Real-Time PCR System with Taqman Universal PCR Master Mix and commercially available TaqMan human gene expression assays (ThermoFischer Scientific; Waltham, MA) for protein phosphatase 2 regulatory subunit B gamma (PPP2R5C; AssayID:Hs00604899_g1) and transcription factor $\mathrm{A}$, mitochondrial (TFAM; AssayID:Hs00273372_s1). Assays were performed in accordance with manufacturer instructions: $50{ }^{\circ} \mathrm{C}$ for $2 \mathrm{~min}, 95^{\circ}$ for $10 \mathrm{~min}$, followed by 40 cycles of $95^{\circ} \mathrm{C}$ for $15 \mathrm{~s}$ followed by $60{ }^{\circ} \mathrm{C}$ for $1 \mathrm{~min}$. mRNA content was determined via the comparative $C_{t}$ methodology. Fold changes between $\mathrm{Ob}$ and $\mathrm{L}$ groups were determined via the $2^{-\Delta \Delta \mathrm{Ct}}$ methodology where $\Delta \Delta \mathrm{C}_{\mathrm{t}}=\Delta \mathrm{C}_{\mathrm{t}}$ Obese $-\Delta \mathrm{C}_{\mathrm{t}}$

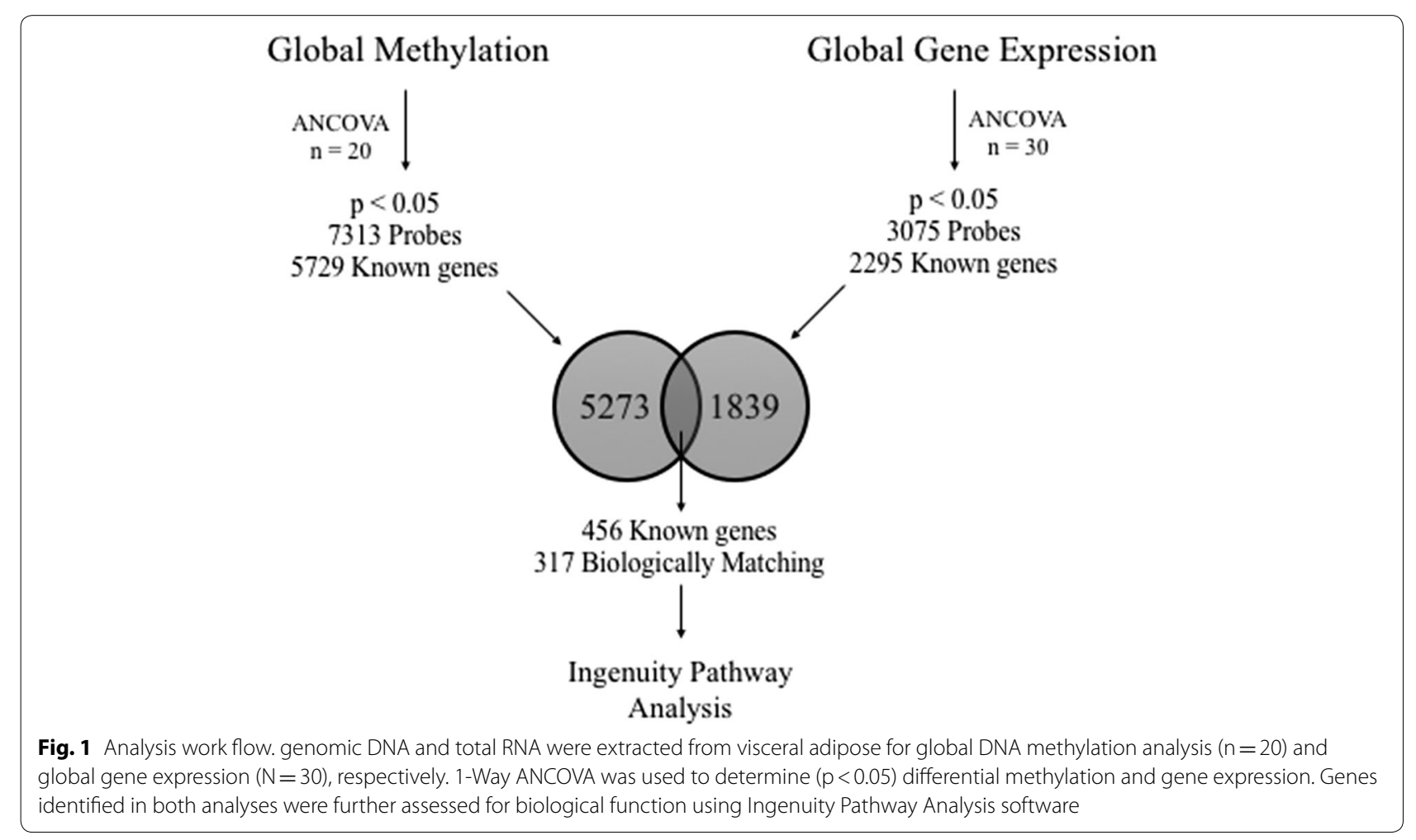


Lean. Assays were run with a multiplexed endogenous control (18S RNA).

\section{Biological pathway analysis}

Ingenuity Pathway Analysis (IPA; Ingenuity, Inc.; Redwood City, CA) was utilized for probe set annotations and to query relationships between genes. For this study, we utilized the canonical pathway analysis tool to identify canonical pathways that were represented in our dataset. Canonical Pathway Analysis utilizes a Right-Handed Tukey's $T$ Test to test for overrepresentation of genes/pathways in datasets in comparison to the knowledgebase.

\section{Other statistical analyses}

Normality of demographic data was assessed with the Shapiro-Wilk test and visualization of the distribution. If data were non-normally distributed, those data were $\log _{2}$ transformed and reassessed for normality. A 2-sample $t$ test was used to assess differences in demographic values between $\mathrm{Ob}$ and L cohorts. Differences between subcohorts for gene expression and DNA methylation were assessed via 2 -sample $t$ test. To maintain independence, subjects represented in DNA methylation cohort were removed from the gene expression cohort for this analysis. Differences in gene expression determined by qPCR were analyzed by via 1-tailed 2-sample $t$ test. Significance was determined a priori as $\mathrm{p}<0.05$. Statistical analyses were performed on commercial software (OriginLab Pro 2015; Northampton, MA).

\section{Results}

\section{Participant characteristics}

Participant characteristics are presented in Table 1. By design, the Ob group had a significantly $(\mathrm{p}<0.05)$ higher body mass and BMI $\left(47 \pm 10 \mathrm{~kg} / \mathrm{m}^{2}\right.$ vs. $\left.22 \pm 3\right)$ than the $\mathrm{L}$ group. Groups were similar in age and matched for ethnicity. The sub-cohort of subjects profiled for DNA methylation was representative (no significant differences in age, body mass, or BMI) of the larger gene expression cohort (Table 1). Both cohorts were similar to the qRTPCR validation cohort $(\mathrm{N}=34)$ for all demographic traits.

\section{Obesity-related changes in VAT global methylation}

Globally, $99.98 \%$ of the probes on the array were detected and included in analyses. Probes that contain a known single nucleotide polymorphism or did not map to a known gene were removed from analysis, leaving 300,460 probes in our analysis. ANCOVA detected 7313 probes mapping to 5729 known genes that were differentially methylated $(\mathrm{p}<0.05)$ in $\mathrm{Ob}$ as compared to L. Methylation differences between $\mathrm{Ob}$ and L VAT ranged from $-22 \%$ to $26 \%$. Stratification of differentially methylated CpG sites found that 1945 (34\%) sites were located in the gene body, $2368(41 \%)$ were located in the promoter region (which includes sites within 1500 and $200 \mathrm{bp}$ of the transcription start site; TSS), 225 (4\%) were located in the $3^{\prime} \mathrm{UTR}, 457(8 \%)$ were located in the 1 st exon, and $734(13 \%)$ were located in the $5^{\prime} \mathrm{UTR}$ region. The full list of differentially regulated $(\mathrm{p}<0.05)$ probes from global methylation analysis can be found in Additional file 2: Table S2.

\section{Obesity-related changes in VAT global gene xpression} ANCOVA detected 3075 probes mapping to 2295 known genes that were differentially expressed $(\mathrm{p}<0.05)$ in $\mathrm{Ob}$ vs L VAT. The full list of differentially regulated $(\mathrm{p}<0.05)$ genes from global gene expression analysis can be found in Additional file 3: Table S3. Significant probes were integrated with methylation results to identify overlap to use for Canonical Pathway Analysis within IPA.

\section{Integration of global methylation and gene expression data}

Gene lists from methylation and gene expression analyses were combined to identify overlapping genes (Fig. 1). In total, 456 genes were identified in both analyses represented by 603 methylation probes and 508 gene expression probes (See Additional file 4: Table S4). Probes were then filtered for directionality of change: genes with methylation probes with a negative $\beta_{\text {diff }}$ (indicating hypomethylation in $\mathrm{Ob}$ ) and gene expression probes with a positive fold change (indicating overexpression in $\mathrm{Ob}$ ), and vice versa. After filtering, 317 probes remained for biological pathway analysis. The top overlapping genes in $\mathrm{Ob}$ as compared to L VAT are presented in Table 2; the full list of overlapping probes for methylation and gene expression is presented in Additional file 4: Table S4.

\section{Methylation and gene expression changes in PI3K/AKT signaling are altered in obesity}

Differentially regulated genes identified in our overlapping methylation/gene expression analysis were further analyzed using pathway analysis (Fig. 2a). Of the 317 probes identified as different between groups in both methylation and expression, 262 were annotated in the IPA databank. We identified PI3K/AKT signaling $\left(\mathrm{p}=1.83 \times 10^{-6} ; 11\right.$ of 121 genes in the canonical pathway were in the dataset) to be significantly over represented in our gene list (Fig. 2b). Methylation and gene expression values for PI3K/AKT Signaling probes are listed in Table 3. To confirm these findings, we confirmed two genes (PPP2R5C and TFAM) from the PI3K/AKT signaling pathway via traditional qPCR. Statistical analysis indicated a significant increase in VAT expression of TFAM 
Table 2 CpG Sites with highest \% methylation differences and corresponding gene expression

\begin{tabular}{|c|c|c|c|c|c|c|c|}
\hline Gene symbol & Probe ID & CpG location & p-value (Ob vs. L) & $\begin{array}{l}\text { Methylation } \\
\text { difference }(\mathrm{Ob}-\mathrm{L})\end{array}$ & Probeset ID & $\begin{array}{l}\text { p-value (Ob } \\
\text { vs. L) }\end{array}$ & Fold change \\
\hline NEDD4L & $\operatorname{cg} 18971282^{b}$ & 5'UTR & $<0.01$ & -16.6 & 212448_at & 0.03 & 3.68 \\
\hline MAPT & $\operatorname{cg} 18228076^{b}$ & $5^{\prime}$ UTR & 0.04 & -4.7 & 233117_at & 0.01 & 3.14 \\
\hline LFNG & $\operatorname{cg} 20572537^{\mathrm{a}}$ & Body & 0.04 & -3.8 & 215270_at & 0.03 & 2.26 \\
\hline SMARCA1 & $\operatorname{cg} 10076009^{b}$ & Body & 0.05 & -3.7 & 215294_s_at & 0.03 & 2.29 \\
\hline PARVA & $\operatorname{cg} 15123662^{b}$ & Body & 0.02 & -3.4 & 235279_at & 0.04 & 2.31 \\
\hline PDZD2 & $\operatorname{cg} 22461201^{b}$ & TSS1500 & 0.01 & -3.2 & 209493_at & 0.04 & 2.70 \\
\hline EXOC4 & $\operatorname{cg} 25467879^{b}$ & Body & 0.02 & -3.2 & 240528_s_at & 0.01 & 2.32 \\
\hline SIPA1L1 & cg02058870 & $5^{\prime}$ UTR & 0.04 & -2.6 & 202254_at & 0.03 & 4.60 \\
\hline ACSF3 & cg05521982 & TSS1500 & 0.02 & -2.4 & 227464_at & 0.02 & 1.79 \\
\hline \multirow[t]{2}{*}{ GNG7 } & $\mathrm{cg} 08481112^{\mathrm{b}}$ & 5'UTR & 0.01 & -2.0 & 228831_s_at & 0.04 & 2.01 \\
\hline & $\operatorname{cg} 19382697^{a}$ & $5^{\prime}$ UTR & & -1.1 & & & \\
\hline \multirow[t]{3}{*}{ KCNT1 } & cg03358588 & Body & 0.05 & 1.5 & 1569462_x_at & 0.01 & -2.61 \\
\hline & cg01841415 & Body & 0.03 & 2.0 & & & \\
\hline & $\operatorname{cg} 13463516^{b}$ & Body & 0.02 & 3.2 & & & \\
\hline OSBPL1A & $\operatorname{cg} 27638913^{b}$ & Body & 0.04 & 3.3 & 1554646_at & 0.04 & -1.87 \\
\hline PPP2R2C & cg23195028 & Body & 0.01 & 3.3 & 223573_s_at & 0.01 & -4.64 \\
\hline $\mathrm{JPH} 3$ & cg04769798 & Body & 0.05 & 3.3 & 229294_at & 0.01 & -2.64 \\
\hline GOLGA3 & $\operatorname{cg} 23755933^{a}$ & $3^{\prime}$ UTR & 0.03 & 3.3 & 1554987_at & 0.04 & -1.54 \\
\hline TTLL9 & $\operatorname{cg} 09044785^{b}$ & $5^{\prime}$ UTR & 0.05 & 3.7 & 234337_at & 0.02 & -1.41 \\
\hline \multirow[t]{2}{*}{ BAl1 } & cg25473866 & Body & 0.01 & 2.1 & 206083_at & - & -1.68 \\
\hline & $\operatorname{cg} 21934273^{a}$ & Body & 0.01 & 3.8 & & & \\
\hline SAMD3 & cg09345868 & $5^{\prime}$ UTR & 0.01 & 4.3 & 1553876_at & 0.04 & -1.70 \\
\hline PPP2R1B & $\operatorname{cg} 09085632^{\mathrm{a}}$ & TSS200 & 0.04 & 5.6 & 222351_at & 0.02 & -2.33 \\
\hline
\end{tabular}

Data are presented as mean \pm SD

Methylation difference: \% methylation (Ob) - \% Methylation ( $\mathrm{L}$ ); values for \% Methylation of groups are located in Additional file 4: Table S4. Significant probes from global DNA methylation analysis and global gene expression analysis were overlaid for matching genes; Probeset ID represents a single gene that may contain multiple methylation ( $\mathrm{CpG}$ ) sites. The top hypo- and hypermethylated probes are presented with corresponding gene probe

a Infinium I probe design

b Infinium II probe design. Gene names are located in Additional file 4: Table S4

$(\mathrm{p}=0.03, \mathrm{FC}=1.8)$ and PPP2R5C $(\mathrm{p}=0.03, \mathrm{FC}=2.6)$ in the Ob group as compared to the L group (Fig. 3).

\section{Discussion}

Visceral adipose tissue is a metabolically active endocrine organ that has been linked to the development of obesity and obesity-related comorbidities [25, 26]. Understanding the epigenetic and molecular differences in VAT of adolescents with obesity in comparison to lean counterparts may help identify potential therapeutic targets and further inform our understanding of tissue dysfunction in obesity. A unique aspect of our study was the use of an adolescent and female cohort which was age and ethnicity matched with lean patients. Identifying changes in VAT methylation in adolescent obesity also removes the environmental influence that significant portions of time in an obesogenic and comorbid environment that may complicate studies in adults. Our goal was not to replicate or confirm findings from those of adult studies $[11-15,17]$, but to explore the patterns of VAT in adolescent obesity which allows us to identify epigenetic and molecular changes in target tissue and during the earlier stages of obesity. Lastly, given the sex disparities present in cardiovascular disease risk and mortality [27], and that women represent $\sim 80 \%$ of bariatric surgery patients [28], identifying these changes in a female cohort holds potential to further understanding obesity related sex disparities.

\section{Global DNA methylation analysis and gene expression analysis}

Similar to other published work $[8,9,13]$, and using a similar [8] or larger cohort [9], we identified 7313 differentially methylated CpG sites mapping to over 5000 genes. Further, $41 \%$ of these CpG sites were located in the promoter region (within $1500 \mathrm{bp}$ of the TSS) while another $34 \%$ were located in the gene body of their 
$\mathbf{a}$

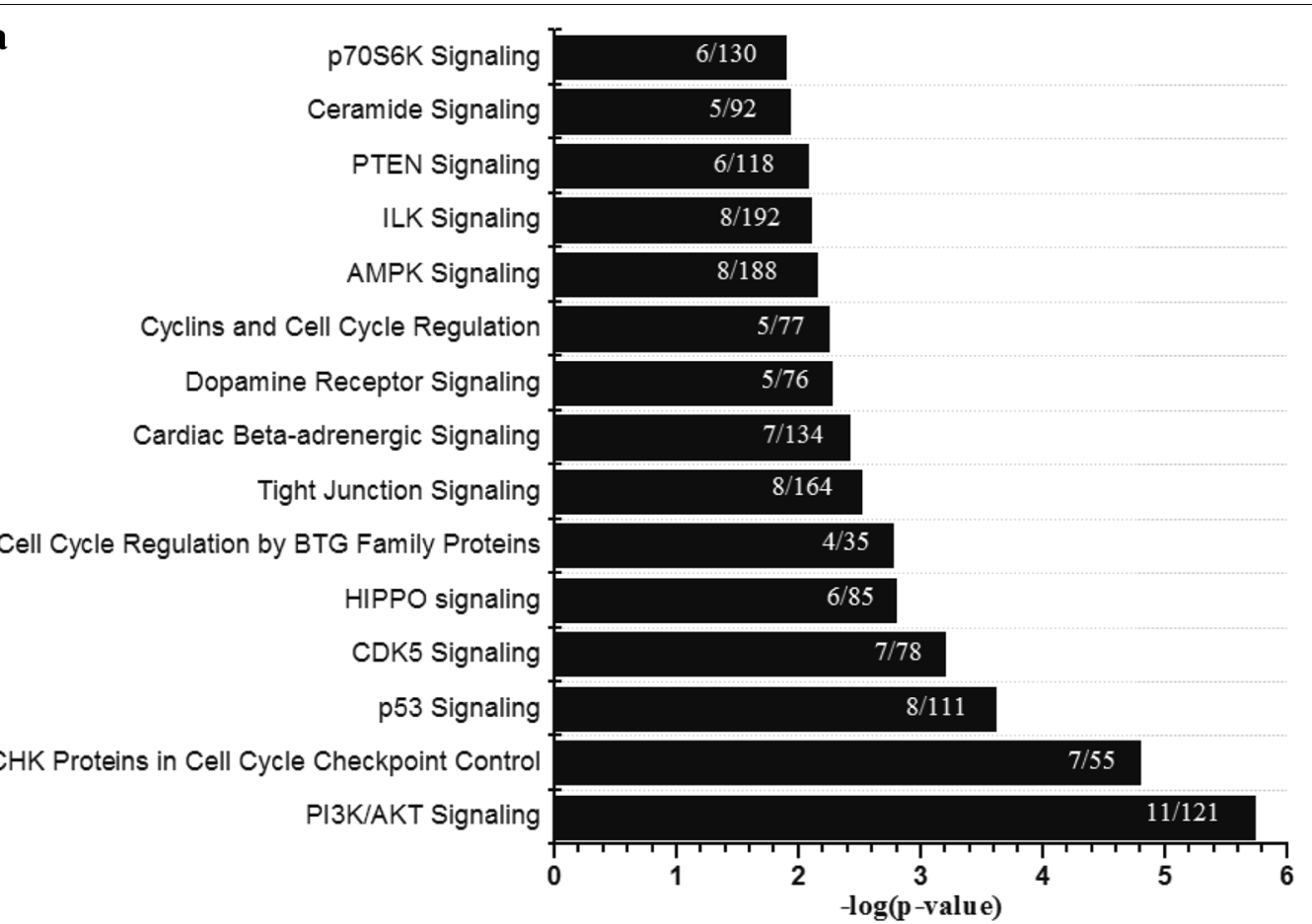

b

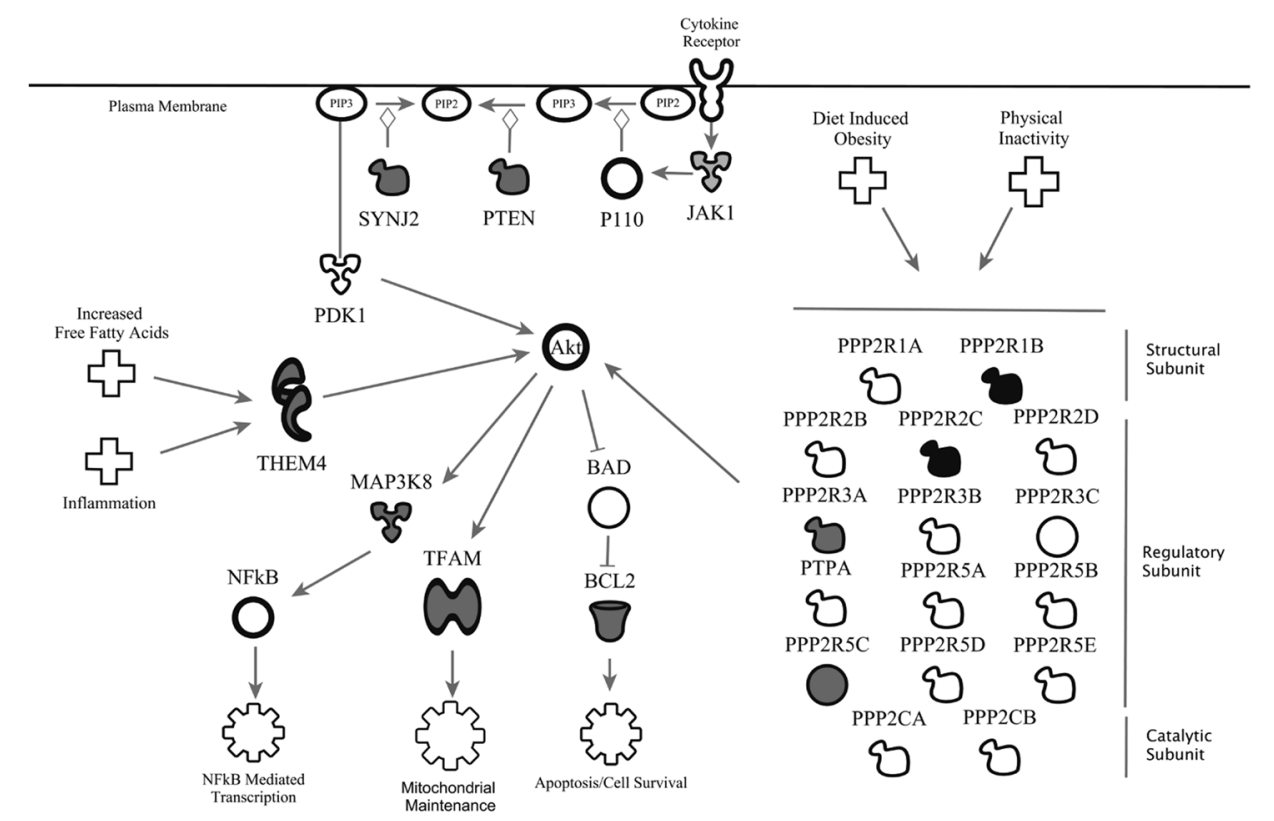

Fig. 2 a Top Canonical Pathways from Ingenuity Pathway Analysis. p-values were determined via Right-Tailed Fisher's Exact Test and -log transformed. A larger-log(p-value) indicates a lesser likelihood that the grouping of significant genes within the pathway is by random chance. Numbers within bars indicate the ratio of significant genes to total genes within the pathway. b Modified IPA PI3K/AKT signaling with obesity. Genes identified in the integrated analysis of global methylation and global gene expression involved in the PI3K/AKT signaling pathway. Gray shading indicates mRNA upregulation in obesity. Black shading indicates mRNA downregulation in obesity. Corresponding Beta-values, p-values and fold changes are located in Table 3. Figure created using Ingenuity Pathway Analysis 
Table 3 PI3K/Akt signaling related genes

\begin{tabular}{|c|c|c|c|c|c|c|c|}
\hline Gene symbol & Probeset ID & CpG location & $\begin{array}{l}\text { p-value (Ob } \\
\text { vs. L) }\end{array}$ & $\begin{array}{l}\text { Methylation } \\
\text { difference }(\mathrm{Ob}-\mathrm{L})\end{array}$ & Probeset ID & $\begin{array}{l}\text { p-value (Ob } \\
\text { vs. L) }\end{array}$ & Fold change \\
\hline $\mathrm{BCL} 2$ & $\operatorname{cg} 07111678^{a}$ & TSS1500 & 0.04 & -0.33 & 203685_at & 0.04 & 2.5 \\
\hline JAK1 & $\operatorname{cg} 25020373^{a}$ & TSS200 & 0.01 & -0.70 & 240613_at & 0.03 & 2.4 \\
\hline MAP3K8 & $\operatorname{cg} 03807314^{b}$ & TSS200 & 0.04 & -0.19 & 235421_at & 0.04 & 1.9 \\
\hline PPP2R1B & $\mathrm{cg} 09085632^{\mathrm{a}}$ & TSS200 & 0.04 & 5.62 & 222351_at & 0.02 & -2.3 \\
\hline PPP2R2C & $\operatorname{cg} 23195028^{b}$ & Body & 0.01 & 3.31 & 223573_s_at & 0.01 & -4.6 \\
\hline PPP2R3A & $\operatorname{cg} 24636867^{a}$ & TSS200 & 0.04 & -0.34 & 207749_s_at & 0.02 & 2.6 \\
\hline PPP2R5C & $\operatorname{cg} 18997701^{b}$ & Body & 0.02 & -0.29 & 1557718_at & 0.01 & 2.2 \\
\hline PTEN & $\operatorname{cg} 08602305^{\mathrm{a}}$ & $5^{\prime} \cup T R$ & 0.03 & -0.31 & 233254x_at & 0.02 & 6.1 \\
\hline SYNJ2 & $\operatorname{cg} 03682872^{\mathrm{a}}$ & TSS200 & 0.03 & -0.35 & 216180_s_at & 0.04 & 1.5 \\
\hline THEM4 & $\operatorname{cg} 03147210^{a}$ & TSS200 & 0.05 & -0.52 & 229253_at & 0.03 & 1.7 \\
\hline TFAM ${ }^{c}$ & cg03859893 & TSS200 & 0.05 & -1.02 & 238443_at & 0.05 & 2.5 \\
\hline
\end{tabular}

Data are presented as mean \pm SD

Methylation Difference: \% Methylation (Ob)- \% Methylation (L); values for \% methylation of groups are located in Additional file 4: Table S4. Significant probes from global DNA methylation analysis and global gene expression analysis were overlaid for matching genes; Probeset ID represents a single gene that may contain multiple methylation (CpG) sites. IPA Canonical Pathway tool identified PI3K/AKT Signaling as significantly overrepresented in our significant gene list

a Infinium I probe design

b Infinium II probe design

c Indicates genes validated via qPCR. Gene names are located in Additional file 4: Table S4

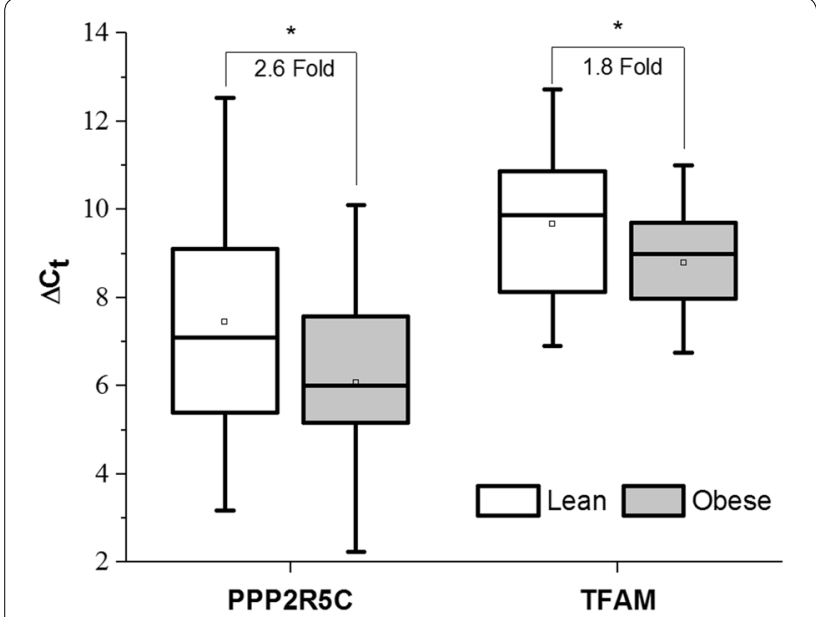

Fig. 3 qRT-PCR Confirmation of Select PI3K/Akt Genes. Relative mRNA content of protein phosphatase 2 regulatory subunit $B$ gamma (PPP2R5C) and transcription factor A, mitochondrial (TFAM) in VAT of lean (white) and persons with obesity (gray) via qRT-PCR. Data are presented as the mean $\pm S D$ of the $\Delta C_{t}\left(C_{t}\right.$ target gene $-C_{t}$ endogenous control) for each group. The mean $\Delta C_{t}$ for each group is indicated by the open box within each box plot. Lower $\Delta C_{t}$ indicates a higher expression. ${ }^{*} p<0.05$ via 1 -tailed two-sample t-test

known genes. We concurrently showed significant differences in 2295 genes through global gene expression analysis. As previous studies $[8,9,13]$ have demonstrated, we show differential methylation in the promoter region with obesity that corresponds to differential gene expression. Promoter region methylation has previously been demonstrated to drive metabolic improvement of skeletal muscle following weight loss [10] while gene body methylation is believed to promote alternative slicing or silencing of alternative promoter sites [29]. Furthermore, and similar to Crujeiras et al. [30], biological interpretation of our genes of interest identify inflammatory and growth pathways. However, there is still a significant amount left to understand about the effect of cell and tissue specific methylation patterns. The degree to which methylation occurs in a particular gene or a particular site is highly variable between cell types and individuals complicating the fully understand the magnitude of differential methylation (Beta difference) of a given site between groups and in different genes. Furthermore, the relationship between specific CpG sites and corresponding mRNA levels remains elusive [15, 31]. Our data indicates clear differences in DNA methylation and gene expression patterns in VAT of adolescent females with obesity, indicating a role for epigenetics in driving obesity related changes in gene and tissue function.

\section{Hyper- and hypomethylation in PI3K/AKT signaling genes} Pathway analysis identified PI3K/AKT signaling as the top canonical pathway represented in our overlapping list of methylation sites/gene expression (Fig. 3a, b; Table 3). All but one of the identified PI3K/AKT genes showed differential methylation in the promoter or gene body, adding to the biological relevance. AKT has a well-defined role in glucose uptake in skeletal muscle and adipose tissue [32]. Pathway components included in our gene set 
are four (PPP2R1B, PPP2R2C, PPP2R3A, and PPP2R5C) of the 16 genes that encode the heterotrimeric protein phosphatase 2 (PP2A). PP2A is a highly conserved serine/threonine phosphatase involved in the regulation of numerous kinases [33] including AKT. Jun et al. [34] showed that PP2A was overexpressed in VAT from rats fed a high fat diet and this resulted in roughly $67 \%$ reduction in phosphorylated (i.e. activated) AKT. While we did not measure total PP2A concentrations, we do provide evidence for differential regulation of PP2A genes (-4.6-fold to 2.6 -fold) via DNA methylation $(-0.34 \%$ to $5.6 \%)$ in Ob VAT as compared to L VAT. Interestingly, PPP2R5C knockout mice have previously been shown to have age-associated obesity [35], though this is likely due to decreased locomotive capacity caused by a heart defect associated with the model. More recently, Cheng et al. [36] showed that expression of PPP2R5C in the liver correlated with obesity and insulin resistance in patients with obesity with or without diabetes, while knockdown in mice resulted in improved glucose metabolism and alter lipid metabolism. Given the metabolic dysfunction associated with obesity, our finding of a 2.2-fold higher expression of PPP2R5C in VAT of $\mathrm{Ob}$ as compared to $\mathrm{L}$ subjects would further support the conclusion of Cheng et al. [36] that $P P P 2 R 5 C$ is a potential metabolic regulator. Further, obesity associated changes in PPP2R5C may be drive by obesity-associated methylation changes.

We also identified three other PI3K/AKT Signaling related genes previously shown to have significant metabolic and inflammatory effects. Phosphatase and tensin homolog (PTEN) was found to be hypomethylated and 6.1-fold higher gene expression in Ob VAT as compared to L. The role of PTEN in obesity and metabolic dysfunction remains unclear with studies showing constitutive over-expression resulting in improved energy expenditure (through adipose browning), improved glucose homeostasis, and longer lifespans [37] while adiposespecific deletion [38] also results in improved metabolic parameters. Of further interest are the results of Pal et al. [39] that indicate increased risk for obesity and cancer, but a decreased risk for T2DM (mediated through improved insulin sensitivity) in PTEN haploinsufficiency. Our analysis also identified mitogen-activated protein kinase kinase kinase 8 (MAP3K8), thioesterase superfamily member 4 (THEM4), and transcription factor A, mitochondrial (TFAM) as having differential methylation and gene expression in Ob VAT. MAP3K8 (also referred to as TPL2) was previously shown to be overexpressed in subcutaneous adipose (SQ) tissue from patients with obesity and this correlated with elevated levels of the inflammatory proteins IL- $1 \beta$, IL-6, and IL-8 [40]. Further exploration of the role of MAP3K8 in 3T3-L1 and human adipocytes showed activation by inflammatory mediators
IL- $1 \beta$ and TNF- $\alpha$, which affected both lipolysis and ERK signaling [41]. THEM4 (also referred to as CTMP) binds to a regulatory domain of AKT, thus preventing its phosphorylation and activation. Here we show VAT from individuals with obesity to have 1.7 -fold higher THEM4 mRNA than lean counterparts. In response to free-fatty acids and inflammatory mediators, THEM4 invokes inhibition of AKT by in immune cells [42] and may participate in the development of impaired insulin resistance in adipocytes [43].

TFAM is a key mitochondrial transcription factor important to the activation of mitochondrial transcription. Adipose specific deletion of TFAM has been shown to result in protection against obesity and insulin resistance [44] while adiponectin-TFAM-knockout mice were resistant to diet-induced weight gain but suffered from various metabolic abnormalities [45]. Obesity-induced mitochondrial dysfunction is a hallmark in multiple tissues and a primary target of pharmaceutical treatment $[46,47]$. To our knowledge, this is the first study to show evidence of DNA methylation driven changes in TFAM mRNA in VAT of individuals with obesity.

While we believe the results and discussion presented in this study are important in furthering the understanding of epigenetic and molecular changes in VAT in obesity, we acknowledge several potential limitations. Only patients with obesity were on a protein-sparing modified fast (as required by the bariatric weight-loss surgical program) and given the environmental responsiveness of DNA methylation and gene expression, we cannot dismiss that potential influence of this diet on our findings, especially since PI3K signaling has been shown to be responsive to such diets [48]. However, the response seems to be tissue- [49] and diet-specific [50]. Given the biological role of the PI3K/Akt pathways in cellular growth and hypertrophy, we suspect, much like the results of Mercken et al. [37], the diet would have the effect of "normalizing" PI3K/Akt signaling in persons with obesity, which would mean that the differences we found between groups would have been larger if we analyzed samples from pre-diet patients with obesity. We were also unable to assess other potential environmental influences such as physical activity levels or smoking status, which have been shown to influence DNA methylation. Lastly, as obesity significantly increases the risk for and presence of comorbidities we were unable to effectively control for the range of comorbid conditions present.

Given the sex disparities of cardiovascular disease risk and mortality [27], we consider this use of an all-female cohort a strength of our study, but studies include male subjects to confirm and expand are findings are needed. Further, we did not assess menstrual phase of the patients 
at the time of the tissue collection (which was logistically impossible for the Lean cohort), though all subjects were post-menarche. Finally, we do not have protein data showing the downstream effects on the reported pathways, as the primary goal of the project was to describe epigenetic changes in obese VAT and how these effects carry over into functional transcriptional changes. Given the invasive nature of VAT collection, we had limited amounts of tissue to work with (especially in Lean controls) to cover both methylome and transcriptome changes, so we did not have extensive tissue remaining for protein studies. Now that we have identified key pathways modified by obesity, future mechanistic studies can address complex protein level changes using a systems biology model.

\section{Conclusion}

VAT has long been recognized as a metabolically active and an endocrine-like tissue that releases inflammatory proteins, cytokines, and adipokines. Using unbiased global molecular profiling technologies, we identified obesity-related gene expression changes paired with changes in DNA methylation, noting coordinated changes in the PI3K/AKT signaling pathway, suggesting that PI3K/AKT signaling pathway dysfunction in obesity may be driven in part by DNA methylation as a result of obesity. Further studies should consider the magnitude of obesity by exploring differences in VAT DNA methylation and gene expression profiles in those with low-risk, moderate-risk, and high-risk obesity. Doing so may help identify methylation loci and genes driving more sever obesity. Further elucidation of the role of DNA methylation in the pathogenesis of obesity-mediated diseases may provide insight into potential therapeutic targets or treatment strategies, especially during early disease development.

\section{Supplementary information}

Supplementary information accompanies this paper at https://doi. org/10.1186/s13098-019-0494-y.

Additional file 1: Table S1. PCR confirmation cohort clinical characteristics.

Additional file 2: Table S2. Differentially regulated DNA methylation probes from global DNA methylation analysis.

Additional file 3: Table S3. Differentially regulated genes from global gene expression analysis.

Additional file 4: Table S4. All overlapping probes/genes from DNA methylation and global gene expression analysis.

\section{Acknowledgements}

The authors would like to acknowledge Jelena Pervanovic Ph.D. for assistance with methylation data analyses and Margaret Morrison for her assistance with the project.

\section{Authors' contributions}

All authors have agreed to be accountable for all aspects of this work including the accuracy and integrity of all data and information. All authors have given final approval of this manuscript for publication. MDB, EPN, MJH were involved in all aspects of this manuscript. SS and RL were involved with sample collection and sample processing. SS, RL, and BH were all involved in the production and analysis of data along with production of the final manuscript. All authors read and approved the final manuscript.

\section{Funding}

This project was supported by Award Number UL1TR000075 (MJH) from the NIH National Center for Advancing Translational Sciences and T32AR065993 (MDB) from the National Institute of arthritis and Musculoskeletal and Skin Diseases. Project contents are solely the responsibility of the authors and do not necessarily represent the official views of the National Center for Advancing Translational Sciences, National Institute of Arthritis and Musculoskeletal and Skin Disease, or the National Institutes of Health. The funders had no role in study design, data collection, and data interpretation.

\section{Availability of data and materials}

Gene expression microarray data have been archived to the Gene Expression Omnibus (GSE88837). Methylation microarray data have been archived to the Gene Expression Omnibus (GSE88940). Other data, to the extent reasonable for the protection of Private Health Information, may be available upon request.

\section{Ethics approval and consent to participate}

Subjects provided written assent to participation and their legal guardians signed a written informed consent as approved by Children's National Health System Institutional Review Board (Protocol ID: Pro00000358). All research activities were in accordance with the Declaration of Helsinki.

\section{Consent for publication \\ Not applicable.}

\section{Competing interests}

The authors declare that they have no competing interests.

\section{Author details}

${ }^{1}$ Center for Genetic Medicine Research, Children's Research Institute, Children's National Medical Center, Washington, DC, USA. ${ }^{2}$ Sheikh Zayed Institute for Pediatric Surgical Innovation, Children's Research Institute, Children's National Medical Center, Washington, DC, USA. ${ }^{3}$ Division of Pediatric Surgery, Children's National Medical Center, Washington, DC, USA. ${ }^{4}$ Department of Integrative Systems Biology, School of Medicine, George Washington University, Washington, DC, USA. ${ }^{5}$ Department of Kinesiology, Indiana University Purdue University Indianapolis, Indianapolis, IN, USA.

Received: 16 August 2019 Accepted: 13 November 2019 Published online: 27 November 2019

\section{References}

1. Bjorntorp P. Metabolic implications of body fat distribution. Diab Care. 1991;14(12):1132-43.

2. Despres JP, Lemieux I. Abdominal obesity and metabolic syndrome. Nature. 2006;444(7121):881-7.

3. Wajchenberg BL. Subcutaneous and visceral adipose tissue: their relation to the metabolic syndrome. Endocr Rev. 2000;21 (6):697-738.

4. Bays H. Central obesity as a clinical marker of adiposopathy; increased visceral adiposity as a surrogate marker for global fat dysfunction. Curr Opin Endocrinol Diab Obes. 2014;21(5):345-51.

5. O'Rahilly S. Human genetics illuminates the paths to metabolic disease. Nature. 2009;462(7271):307-14.

6. Lavebratt C, Almgren M, Ekstrom TJ. Epigenetic regulation in obesity. Int J Obes (Lond). 2012;36(6):757-65.

7. Barres R, Zierath JR. DNA methylation in metabolic disorders. Am J Clin Nutr. 2011;93(4):897S-900S.

8. Barajas-OImos F, Centeno-Cruz F, Zerrweck C, Imaz-Rosshandler I, Martinez-Hernandez A, Cordova EJ, et al. Altered DNA methylation in 
liver and adipose tissues derived from individuals with obesity and type 2 diabetes. BMC Med Genet. 2018;19(1):28.

9. Nilsson E, Jansson PA, Perfilyev A, Volkov P, Pedersen M, Svensson MK, et al. Altered DNA methylation and differential expression of genes influencing metabolism and inflammation in adipose tissue from subjects with type 2 diabetes. Diabetes. 2014;63(9):2962-76.

10. Barres R, Kirchner H, Rasmussen M, Yan J, Kantor FR, Krook A, et al. Weight loss after gastric bypass surgery in human obesity remodels promoter methylation. Cell Rep. 2013;3(4):1020-7.

11. Ronn T, Volkov P, Davegardh C, Dayeh T, Hall E, Olsson AH, et al. A six months exercise intervention influences the genome-wide DNA methylation pattern in human adipose tissue. PLoS Genet. 2013;9(6):e1003572.

12. Keller M, Kralisch S, Rohde K, Schleinitz D, Dietrich A, Schon MR, et al. Global DNA methylation levels in human adipose tissue are related to fat distribution and glucose homeostasis. Diabetologia. 2014;57(11):2374-83.

13. Guenard F, Tchernof A, Deshaies Y, Perusse L, Biron S, Lescelleur O, et al. Differential methylation in visceral adipose tissue of obese men discordant for metabolic disturbances. Physiol Genomics. 2014;46(6):216-22.

14. Keller M, Hopp L, Liu X, Wohland T, Rohde K, Cancello R, et al. Genomewide DNA promoter methylation and transcriptome analysis in human adipose tissue unravels novel candidate genes for obesity. Mol Metab. 2017:6(1):86-100.

15. Kurylowicz A, Owczarz M, Polosak J, Jonas MI, Lisik W, Jonas M, et al. SIRT1 and SIRT7 expression in adipose tissues of obese and normal-weight individuals is regulated by microRNAs but not by methylation status. Int J Obes (Lond). 2016;40(11):1635-42.

16. Turcot $V$, Tchernof A, Deshaies Y, Perusse L, Belisle A, Marceau S, et al. LINE-1 methylation in visceral adipose tissue of severely obese individuals is associated with metabolic syndrome status and related phenotypes. Clin Epigenetics. 2012;4(1):10.

17. Benton MC, Johnstone A, Eccles D, Harmon B, Hayes MT, Lea RA, et al. An analysis of DNA methylation in human adipose tissue reveals differential modification of obesity genes before and after gastric bypass and weight loss. Genome Biol. 2015;16:8.

18. Rzehak P, Covic M, Saffery R, Reischl E, Wahl S, Grote V, et al. DNA-Methylation and body composition in preschool children: epigenome-wideanalysis in the European Childhood Obesity Project (CHOP)-Study. Sci Rep. 2017;7(1):14349.

19. Huang RC, Garratt ES, Pan H, Wu Y, Davis EA, Barton SJ, et al. Genomewide methylation analysis identifies differentially methylated CpG loci associated with severe obesity in childhood. Epigenetics. 2015;10(11):995-1005.

20. Group TABPW. Expression profiling — best practices for data generation and interpretation in clinical trials. Nat Rev Genet. 2004;5(3):229.

21. Du P, Zhang X, Huang CC, Jafari N, Kibbe WA, Hou L, et al. Comparison of Beta-value and $\mathrm{M}$-value methods for quantifying methylation levels by microarray analysis. BMC Bioinform. 2010;11:587.

22. Team RC. R: A language and environment for statistical computing. 2013.

23. Bibikova M, Barnes B, Tsan C, Ho V, Klotzle B, Le JM, et al. High density DNA methylation array with single $\mathrm{CpG}$ site resolution. Genomics. 2011;98(4):288-95.

24. Chen YA, Lemire M, Choufani S, Butcher DT, Grafodatskaya D, Zanke BW, et al. Discovery of cross-reactive probes and polymorphic CpGs in the illumina infinium humanmethylation450 microarray. Epigenetics. 2013;8(2):203-9.

25. Mathieu P, Poirier P, Pibarot P, Lemieux I, Despres JP. Visceral obesity: the link among inflammation, hypertension, and cardiovascular disease. Hypertension. 2009;53(4):577-84.

26. Castellano-Castillo D, Moreno-Indias I, Sanchez-Alcoholado L, RamosMolina B, Alcaide-Torres J, Morcillo S, et al. Altered adipose tissue DNA methylation status in metabolic syndrome: relationships between global DNA methylation and specific Methylation at adipogenic, lipid metabolism and inflammatory candidate genes and metabolic variables. J Clin Med. 2019:8(1):87.

27. Appelman Y, van Rijn BB, Ten Haaf ME, Boersma E, Peters SA. Sex differences in cardiovascular risk factors and disease prevention. Atherosclerosis. 2015;241(1):211-8.
28. Young MT, Phelan MJ, Nguyen NT. A decade analysis of trends and outcomes of male vs female patients who underwent bariatric surgery. J Am Coll Surg. 2016;222(3):226-31.

29. Lev Maor G, Yearim A, Ast $G$. The alternative role of DNA methylation in splicing regulation. Trends Genet. 2015;31(5):274-80.

30. Crujeiras AB, Diaz-Lagares A, Moreno-Navarrete JM, Sandoval J, Hervas D, Gomez A, et al. Genome-wide DNA methylation pattern in visceral adipose tissue differentiates insulin-resistant from insulin-sensitive obese subjects. Transl Res. 2016:178(13-24):e5.

31. Kurylowicz A, Jonas M, LisikW, Jonas M, Wicik ZA, Wierzbicki Z, et al. Obesity is associated with a decrease in expression but not with the hypermethylation of thermogenesis-related genes in adipose tissues. J Transl Med. 2015;13:31

32. Cong LN, Chen H, Li Y, Zhou L, McGibbon MA, Taylor SI, et al. Physiological role of Akt in insulin-stimulated translocation of GLUT4 in transfected rat adipose cells. Mol Endocrinol. 1997;11(13):1881-90.

33. Millward TA, Zolnierowicz S, Hemmings BA. Regulation of protein kinase cascades by protein phosphatase 2A. Trends Biochem Sci. 1999;24(5):186-91.

34. Jun HS, Hwang K, Kim Y, ParkT. High-fat diet alters PP2A, TC10, and CIP4 expression in visceral adipose tissue of rats. Obesity (Silver Spring). 2008;16(6):1226-31

35. Varadkar P, Despres D, Kraman M, Lozier J, Phadke A, Nagaraju K, et al. The protein phosphatase $2 \mathrm{~A} B 56$ gamma regulatory subunit is required for heart development. Dev Dyn. 2014;243(6):778-90.

36. Cheng YS, Seibert O, Kloting N, Dietrich A, Strassburger K, FernandezVeledo S, et al. PPP2R5C couples hepatic glucose and lipid homeostasis. PLoS Genet. 2015;11(10):e1005561.

37. Ortega-Molina A, Efeyan A, Lopez-Guadamillas E, Munoz-Martin M, Gomez-Lopez G, Canamero M, et al. Pten positively regulates brown adipose function, energy expenditure, and longevity. Cell Metab. 2012;15(3):382-94.

38. Kurlawalla-Martinez C, Stiles B, Wang Y, Devaskar SU, Kahn BB, Wu H. Insulin hypersensitivity and resistance to streptozotocin-induced diabetes in mice lacking PTEN in adipose tissue. Mol Cell Biol. 2005;25(6):2498-510.

39. Pal A, Barber TM, Van de Bunt M, Rudge SA, Zhang Q, Lachlan KL, et al. PTEN mutations as a cause of constitutive insulin sensitivity and obesity. N Engl J Med. 2012;367(11):1002-11.

40. Ballak DB, van Essen P, van Diepen JA, Jansen H, Hijmans A, Matsuguchi T, et al. MAP3K8 (TPL2/COT) affects obesity-induced adipose tissue inflammation without systemic effects in humans and in mice. PLoS ONE. 2014;9(2):e89615.

41. Jager J, Gremeaux T, Gonzalez T, Bonnafous S, Debard C, Laville M, et al. Tpl2 kinase is upregulated in adipose tissue in obesity and may mediate interleukin-1 beta and tumor necrosis factor-\{alpha\} effects on extracellular signal-regulated kinase activation and lipolysis. Diabetes. 2010;59(1):61-70

42. Zhou Q, Leeman $\mathrm{SE}$, Amar S. Signaling mechanisms in the restoration of impaired immune function due to diet-induced obesity. Proc Natl Acad Sci U S A. 2011;108(7):2867-72.

43. Park J, Li Y, Kim SH, Yang KJ, Kong G, Shrestha R, et al. New players in high fat diet-induced obesity: IETM1 and CTMP. Metabolism. 2014;63(3):318-27.

44. Vernochet C, Mourier A, Bezy O, Macotela Y, Boucher J, Rardin MJ, et al. Adipose-specific deletion of TFAM increases mitochondrial oxidation and protects mice against obesity and insulin resistance. Cell Metab. 2012;16(6):765-76.

45. Vernochet C, Damilano F, Mourier A, Bezy O, Mori MA, Smyth G, et al. Adipose tissue mitochondrial dysfunction triggers a lipodystrophic syndrome with insulin resistance, hepatosteatosis, and cardiovascular complications. FASEB J. 2014;28(10):4408-19.

46. Rong JX, Qiu Y, Hansen MK, Zhu L, Zhang V, Xie M, et al. Adipose mitochondrial biogenesis is suppressed in $\mathrm{db} / \mathrm{db}$ and high-fat diet-fed mice and improved by rosiglitazone. Diabetes. 2007;56(7):1751-60.

47. Wilson-Fritch L, Nicoloro S, Chouinard M, Lazar MA, Chui PC, Leszyk J, et al. Mitochondrial remodeling in adipose tissue associated with obesity and treatment with rosiglitazone. J Clin Invest. 2004;114(9):1281-9.

48. Mercken EM, Crosby SD, Lamming DW, JeBailey L, Krzysik-Walker $\mathrm{S}$, Villareal DT, et al. Calorie restriction in humans inhibits the PI3K AKT pathway and induces a younger transcription profile. Aging Cell. 2013;12(4):645-51. 
49. Garaulet M, Viguerie N, Porubsky S, Klimcakova E, Clement K, Langin D, et al. Adiponectin gene expression and plasma values in obese women during very-low-calorie diet. Relationship with cardiovascular risk factors and insulin resistance. J Clin Endocrinol Metab. 2004;89(2):756-60.

50. Viguerie N, Vidal H, Arner P, Holst C, Verdich C, Avizou S, et al. Adipose tissue gene expression in obese subjects during low-fat and high-fat hypocaloric diets. Diabetologia. 2005;48(1):123-31.

\section{Publisher's Note}

Springer Nature remains neutral with regard to jurisdictional claims in published maps and institutional affiliations.
Ready to submit your research? Choose BMC and benefit from:

- fast, convenient online submission

- thorough peer review by experienced researchers in your field

- rapid publication on acceptance

- support for research data, including large and complex data types

- gold Open Access which fosters wider collaboration and increased citations

- maximum visibility for your research: over $100 \mathrm{M}$ website views per year

At BMC, research is always in progress.

Learn more biomedcentral.com/submissions 